\title{
Implications of health and safety legislation for the professional sportsperson
}

\author{
Colin W. Fuller BSc, PhD \\ Centre for Hazard and Risk Management, Loughborough University of Technology, Loughborough LE11 3TU, \\ UK
}

\begin{abstract}
There are a large number of injuries in most professional sports every year, and research interest has usually centred around the medical aspects of these injuries. However, health and safety legislation also applies to professional sport, and it is important, as with any other occupation, to understand the underlying causes of the incidents leading to the injuries and to take steps to minimize future injuries. The introduction of the Management of Health and Safety at Work Regulations 1992 formalized a risk assessment approach to health and safety issues; an approach that has always been implicit in the Health and Safety at Work etc. Act 1974. This review assesses how the relevant UK health and safety legislation impacts on the professional sportsperson.
\end{abstract}

Keywords: sport, health, safety, injuries, legislation

Interest in accidents and injuries suffered by professional sportspersons has increased in recent years as a result of several deaths and serious injuries. This interest was heightened during 1994 by the deaths of a number of leading sportsmen: Steve Wood (horse racing), Ayrton Senna and Roland Ratzenberger (motor racing), and Bradley Stone (boxing). Despite the high level of injury and ill-health in professional sportspersons, the subject is unfortunately generally treated as being somehow different from injury and ill-health in other occupations. However, it should be remembered that the professional sportsperson is subject to the same requirements of health and safety legislation as an employee in most other occupations.

A Health and Safety Executive (HSE) report ${ }^{1}$ on the hidden costs of accidents at work showed that the true costs to an organization can be more than ten times the insured costs recovered. This situation is unlikely to be different in professional sport. For example, 'hidden costs' to a Premier League football club resulting from an injury to a key player may include the following: (1) time spent by medical and training staff during the rehabilitation period; (2) cost of buying a replacement player to cover the period of injury; (3) reduced income from lower match attendance figures; (4) reduced income from lower final league placing; (5) elimination from a cup competi-

Address for correspondence: Colin W. Fuller BSc, PhD, Centre for Hazard and Risk Management, Loughborough University of Technology, Loughborough LE11 3TU, UK tion; (6) failure to qualify for European competition; (7) loss of match and/or elimination from a European competition; (8) loss of advertising revenue; (9) increased insurance costs.

\section{Discussion}

Two major pieces of legislation dominate the management of health and safety issues for all people at work: the Health and Safety at Work (HASAW) Act $1974^{2}$ and the Management of Health and Safety at Work (MHSW) Regulations 1992 ${ }^{3}$. Other Regulations $^{4-7}$ are relevant to this issue but these only amplify and add detail to the general principles raised in the other documents. A third major piece of legislation, the Reporting of Injuries, Diseases and Dangerous Occurrences Regulations (RIDDOR) $1985^{8}$, is also important and has far-reaching consequences.

\section{The Health and Safety at Work etc. Act 1974}

The HASAW Act places duties of a general nature on employers, employees, the self-employed, providers of workplaces and manufacturers of work equipment; it also makes provision for establishing more detailed Regulations in specific areas of health and safety. Part I of the HASAW Act refers to the health, safety and welfare of employees and the self-employed in connection with work. The professional sportsperson is either an employee or self-employed person and, as such, the Act contains several important and relevant sections.

There are a number of general requirements in the Act under Section 2, 'General duties of employers to their employees'. The legislation states that 'it shall be the duty of every employer to ensure, so far as is reasonably practicable, the health, safety and welfare at work of all his employees'. A sportsperson at work includes time during which a sporting event takes place, time before and after the event whilst at the location of the event, time travelling to and from the event if travelling together as a team and time spent training. The term so far as is reasonably practicable is not defined in the Act; however, its meaning has been established in case law. The HSE ${ }^{9}$ and the law courts accept that the statement means:

'the degree of risk in a particular activity or environment can be balanced against the time, 
trouble, cost and physical difficulty of taking measures to avoid the risk. If these are so disproportionate to the risk that it would be unreasonable for the persons concerned to have to incur them to prevent it, they are not obliged to do so'.

The responsibility for preventing injury and ill-health rests with those people who give rise to the risk and employers therefore have an obligation to make the necessary resources available, commensurate with the risks involved, to reduce those risks. By the very nature of all sporting activities, a sportsperson is at greater risk of injury or ill-health than someone not participating in sport. Therefore, employers must demonstrate that they have identified the hazards involved with the sporting activity and assessed the risks associated with these hazards. Unless employers have carried out this duty they can not demonstrate that their actions fit the description of so far as is reasonably practicable. The implementation of this general requirement for risk assessment has been amplified in the MHSW Regulations $1992^{3}$ and is discussed further below.

Section 2 of the HASAW Act also defines the duty of employers to ensure that items of plant provided to carry out work are safe and maintained in a safe condition. The Act defines, in section 53, plant as: 'includes any machinery, equipment or appliance'. So, for example, teams providing racing cars would be expected to ensure that the vehicles, taking into account the speed and race conditions they will be subjected to, are appropriate and maintained in a condition to minimize the risk of accident and injury to the driver. This would include the provision of the correct type of aerodynamic body design, tyres, roll bars and interior design to minimize the risk of injury to the driver in the event of an accident during a race. Requirements covering work equipment are contained in the Provision and Use of Work Equipment Regulations $1992^{5}$.

Under Section 3, 'General duties of employers and self-employed to persons other than their employees' the Act requires every employer and self-employed person to conduct their undertaking in such a way as to ensure, so far as is reasonably practicable, that persons not in their employment are not exposed to risks to their health or safety. This section of the Act is particularly relevant in sport where there is the potential for direct contact or interaction between competitors (Figure 1). The implication is that, for example, team tactics employed within a sporting event should not put the health and safety of another sportsperson at risk. This could be particularly relevant in sports such as rugby, football and ice hockey where aggressive tactics by a team could lead to the injury of opposing players. Many of the laws or rules of a sport are included to reflect, and minimize, the risk of injury or ill-health. Hence, if it is known that a particular action can lead to the injury of a player then the sport's ruling body should change the laws or rules of the sport to make the action unacceptable. For example, the ways in which a player may bowl the ball to a batsman in cricket and the way in which tackles may be made in rugby are restricted in order to minimize the risk of injury.

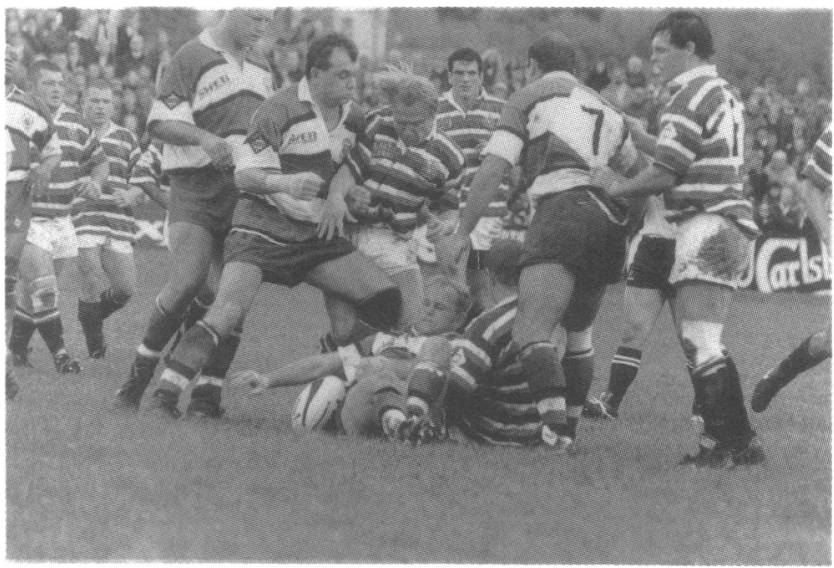

Figure 1.

Arbiters of sporting events, e.g. umpires and referees, have a responsibility to implement the laws and rules of the sport to ensure the health and safety of the participants. Arbiters, who fail to take action against players who commit breaches of the laws of the game, are themselves not implementing their duty of care to the other competitors (Figure 2).

Section 4, 'General duties of persons concerned with premises to persons other than their employees' covers the responsibilities that the operators of venues for sporting events have towards the professional sportsperson and spectators, together with their duty to provide safe places for the event to take place. A sportsperson can reasonably expect to have a sporting arena provided that allows an event to take place with the level of risk of injury or ill-health reduced so far is reasonably practicable to a minimum. This requirement can be illustrated by sports where there could be injury arising from collision with surrounding barriers or as a result of the condition of a playing surface.

Section 6, 'General duties of manufacturers etc. as regards articles and substances for use at work' highlights the responsibility of equipment designers and manufacturers to the professional sportsperson for ensuring that their equipment designs are safe and without

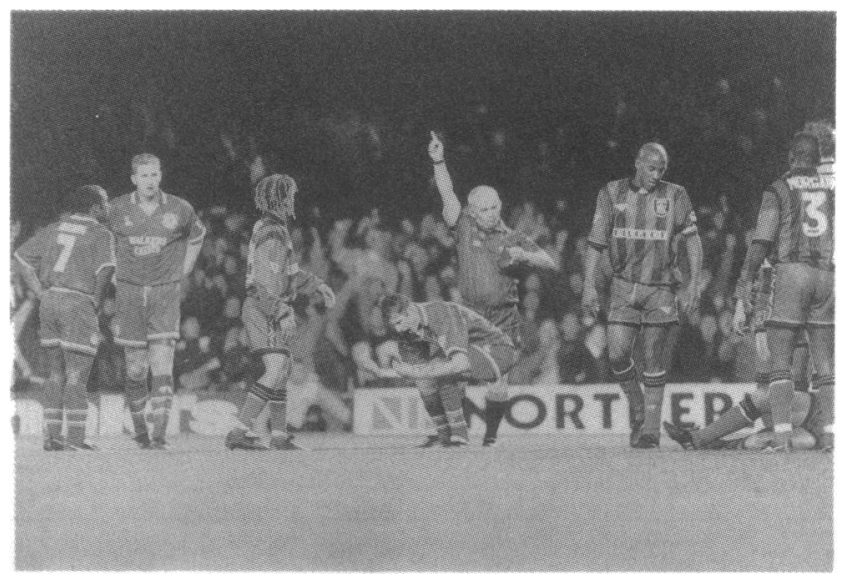

Figure 2. 


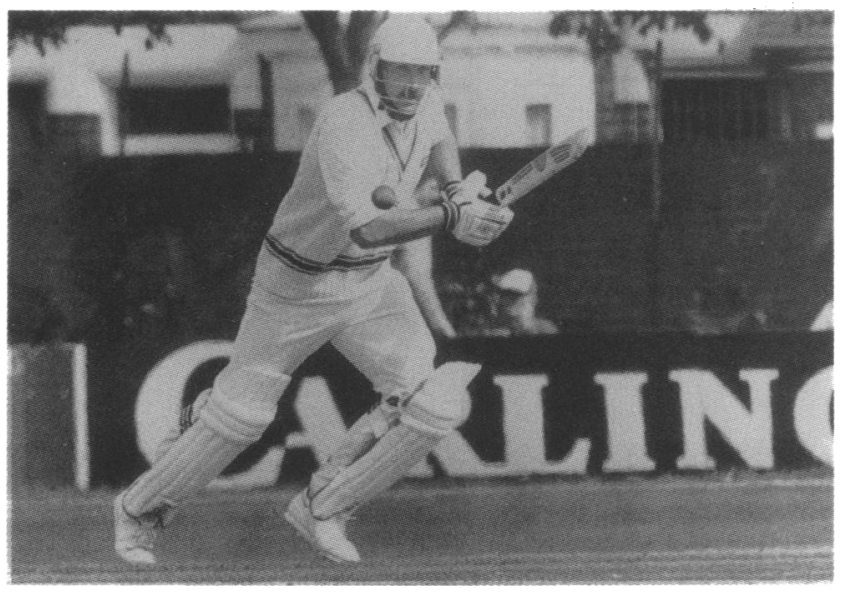

Figure 3.

risk when used. This is a wide ranging responsibility and would include, for example, the need for the correct design of sports shoes to minimize the risk of injury or long-term health problems. The design of protective equipment should also be included in this area of responsibility, for example, cricketers' gloves, helmets and pads (Figure 3); however, surprisingly, the Personal Protective Equipment at Work Regulations $1992^{4}$ excludes protective equipment used during competitive sports.

Section 7, 'General duties of employees at work' has the most wide ranging implications for the sportsperson. There is a legal responsibility defined for employees to not only ensure that they do not put themselves at unnecessary risk of injury but also to ensure that they do not put any other person at risk of injury. The implication here is that provided a sportsperson performs within the laws or rules of the governing body of the sport it can be considered that reasonable care is being taken of their own and others health and safety. However, if there is a transgression of the laws or rules of the sport, and it is reasonably foreseeable that an injury to a sportsperson would result from that transgression, then there is a breach of this section of the Act (Figure 4). This should not

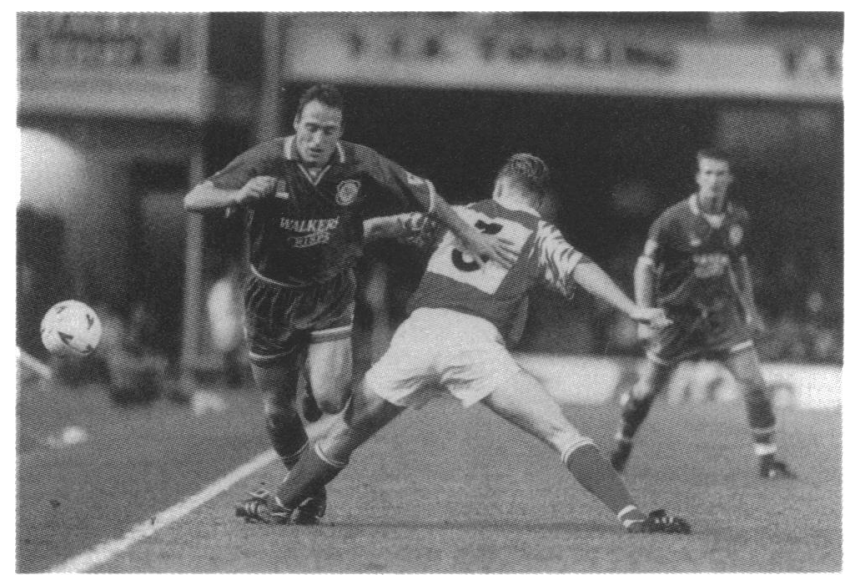

Figure 4. however be confused with assault or causing injury intentionally during competition.

Under Section 47, 'Civil liability', the HASAW Act specifically excludes civil liability for a breach of any of the general duties required under the Act. Therefore, if a sportsperson is injured during competition or training and wishes to claim for compensation their only option is to bring a civil case against an employer, fellow competitor or equipment supplier. In this case, it is necessary for the injured sportsperson to demonstrate a failure by the defendant to show a duty of care to those with whom he came into contact. There has been an increase in the willingness of sportspersons to consider this option using the torts of negligence and assault. A further route open to a sportsperson who has incurred injury during his work, as for any other occupation, is to lodge an industrial injury claim with the Department of Social Security.

\section{The Management of Health and Safety at Work Regulations 1992}

The two main Regulations, within the MHSW Regulations, affecting the professional sportsperson are Regulation 3, Risk assessment and Regulation 5, Health surveillance.

Regulation 3 requires every employer to make a suitable and sufficient assessment of risks to the health and safety of employees and other people affected by their activities. It is essential therefore for employers to ensure that the way in which a sportsperson is expected to carry out the sporting activity, either in competition or in training, is managed in such a way that the sportsperson is not put at risk of injury or ill-health. To satisfy this requirement it is important that the employer is aware of the hazards and risks to which a sportsperson is subjected and to define and implement management systems to minimize the risk of injury and ill-health. For example, an employer should ensure that training schedules have been assessed and are appropriate for out-of-season, pre-season and in-season requirements; efficient warm-up regimes are employed prior to competition; equipment used is fit for the purpose and the sporting stadium is safe for the event taking place.

Routine training schedules often require weight training and this presents an interesting issue under health and safety legislation. The specialized aspects relating to the lifting of weights are covered in the Manual Handling Operations Regulations 19927. These regulations primarily address the problems of lifting heavy loads as part of a work programme rather than the lifting of weights as a means of improving muscle strength. However, the principles and requirements of these regulations, in terms of understanding the risks associated with lifting, are equally valid in sports training.

As a sportsperson is often required to carry out onerous playing schedules, minor injuries received during competition or training may not have time to fully recover between matches. Continuing to play may increase the risk of more serious injury or long-term ill-health. Although the short-term benefits 
for the employer, and on occasions the player, are clear the long-term risks to the health of the sportsperson and to the asset value of the employer should be fully assessed.

An employer is expected to provide the sportsperson with the necessary information on possible injuries and ill-health arising from the sport and then to provide adequate training and supervision to minimize the risk of injury or ill-health. This requirement is of particular importance to a young sportsperson where there is a possibility of over-use or over-extension of muscles and stress being placed on developing bones. The stress placed on the spine in fast bowlers, the knee and leg muscles in skiers and the elbow in tennis players are typical examples. Some sport's controlling bodies actively take steps to instruct young players in these problems but whether sufficient of the sport's resources are channelled in this direction is debatable. A wide discussion also centres around the problem of loss of consciousness during sporting events. There are several known medical problems associated with losing consciousness, and it is arguable that every sportsperson who suffers from loss of consciousness during competition should be withdrawn from participation until a medical adviser has agreed that it is safe for them to continue.

The employer should also arrange for protective equipment to be used and regularly checked, e.g. in horse racing this would include the use of a properly fitted helmet, in football the use of shin pads and in cricket it would be difficult to justify batsmen or close-in fielders not wearing helmets when the risk of head injury from a cricket ball is clearly foreseeable (Figure 5).

Regulation 5, 'Health surveillance' is particularly relevant in sports where long-term health problems can occur to the muscles, joints or bones of a sportsperson. The employer should identify those long-term health problems associated with the sport and carry out an appropriate health surveillance scheme. Where the sportsperson moves from one employer to another, the information regarding their work-related health situation should be made available to the new employer's medical advisers.

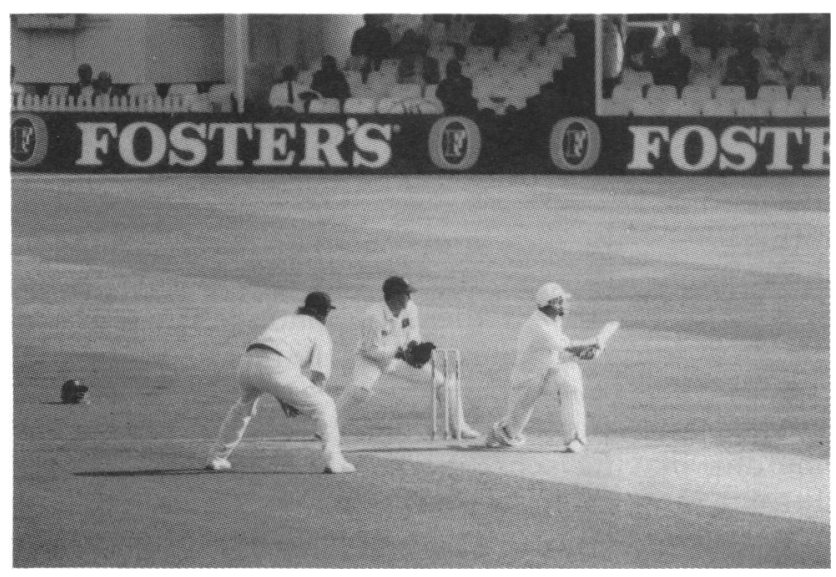

Figure 5.

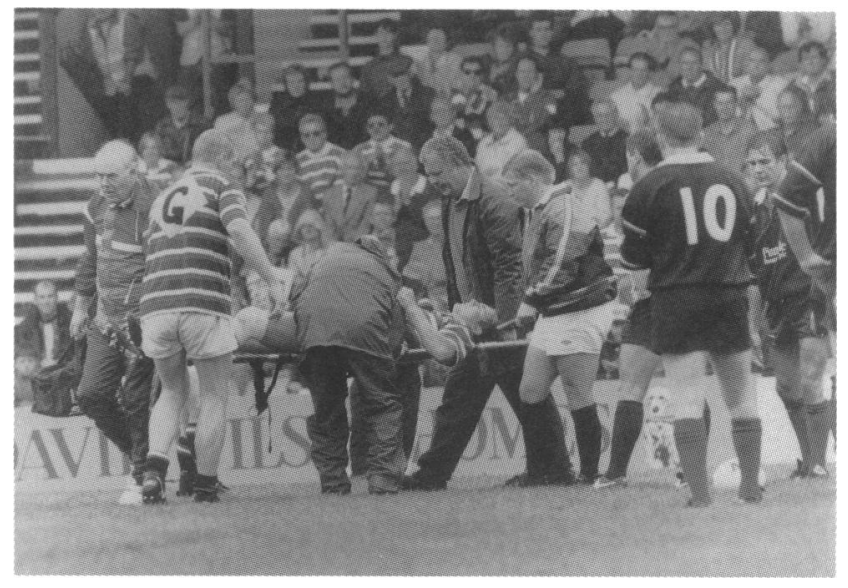

Figure 6.

\section{The Reporting of Injuries, Diseases and Dangerous Occurrences Regulations 1985}

These Regulations ${ }^{8}$ could have the greatest impact on the professional sportsperson if they were fully implemented. One purpose of the Regulations is to provide reports to the HSE or the Local Authority of any events resulting in accidents at work (Figure 6). These Regulations apply to events that arise in connection with work activities covered by the HASAW Act 1974 and therefore, apply to all professional sports.

Regulation 3, 'Notification and reporting of injuries and dangerous occurrences' requires the responsible person to notify in writing the enforcing authority of a death or specified injury resulting from a work activity. The specified injuries referred to are: (1) fracture of the skull, spine, pelvis and any bone in the arm, wrist (but not a bone in the hand), leg or ankle (but not a bone in the foot); (2) amputation of a hand, foot, finger, thumb or toe; (3) the loss of sight of an eye or a penetrating injury to an eye and (4) any other injury which results in the person injured being admitted immediately into hospital for more than 24 hours. There are many sports where accidents occur leading to injuries of the type described above and these injuries should be reported to the appropriate authority.

The responsible person is also required to report cases 'where a person at work is incapacitated for work of a kind which he might reasonably be expected to do, either under his contract of employment, or, if there is no such contract, in the normal course of his work, for more than three consecutive days'. This sub-section of Regulation 3 requires any 'three-day' accident to be reported and would include the case where a sportsperson could not carry out their normal training programme as a result of an injury even though they may still be available for the next scheduled sporting event.

The original intention of RIDDOR was that injuries arising from violence at work should be classified as reportable; however, this aspect of injury at work has not been implemented. However, proposed revisions to these Regulations, by the HSE and anticipated to 
be implemented during 1995, are intended to include injuries arising from acts of violence as reportable injuries. The implications for professional sport, as with other occupations, of reporting an injury as arising from an act of violence and the consequential possibility of civil legal proceedings are most significant.

In conclusion, there are many sports where a risk assessment approach to health and safety issues, as required by the MHSW Regulations, would highlight areas needing improvement. It should not be assumed, however, that studies of health and safety issues in sport will result in detrimental changes to the nature of the sport or will detract from their popular appeal. Instead there are real benefits to everyone associated with sport at all levels. The benefits include: the athlete's risk of injury or ill-health being reduced; the employer's assets being maintained and spectators' enjoyment being increased by having the opportunity to see top athletes competing in more events.

Most occupations have seen an improvement in the health and safety of the workforce as a result of implementing proactive health and safety manage- ment. There is no reason to suggest that professional sport would not benefit in a similar way.

\section{Acknowledgements}

Pictures $1-4$ and 6 are reproduced by permission of the Leicester Mercury Group Ltd and Picture 5 is reproduced by permission of C. Lester.

\section{References}

1 Health \& Safety Executive. The Costs of Accidents at Work, HS(G)96, 1993.

2 Health and Safety at Work etc. Act 1974. London, UK: HMSO.

3 Management of Health and Safety at Work Regulations 1992. London, UK: HMSO, (SI 1992 No 2051).

4 Personal Protective Equipment at Work Regulations 1992. London, UK: HMSO, (SI 1992 No 2966).

5 Provision and Use of Work Equipment Regulations 1992. London, UK: HMSO, (SI 1992 No 2932).

6 Workplace (Health, Safety and Welfare) Regulations 1992. London, UK: HMSO, (SI 1992 No 3004).

7 Manual Handling Operations Regulations 1992. London, UK: HMSO, (SI 1992 No 2793).

8 Reporting of Injuries, Diseases and Dangerous Occurrences Regulations 1985. London, UK: HMSO, (SI 1985 No 2023).

9 Health \& Safety Executive. Successful Health and Safety Management, HS(G)65, 1993.

\section{BASM Merchandise 1995}

$\begin{array}{llr}\text { Ladies scarves } & \text { White with blue border and BASM logo-27-inch square } & £ 5+£ 1 \text { p\&p } \\ & \text { Navy blue with fringe and BASM logo } 54 \times 9 \text { inches (oblong) } & £ 5+£ 1 \text { p\&p } \\ \text { Ties } & \text { Single motif } & £ 6+£ 1 \mathrm{p} \& \mathrm{p} \\ & \text { Multi motif } & £ 6+£ 1 \mathrm{p} \& \mathrm{p} \\ \text { Blazer badge } & \text { Wire }-4 \text { inches high } & £ 5+£ 1 \mathrm{p} \& \mathrm{p} \\ & \text { Wire }-3 \text { inches high } & £ 5+£ 1 \mathrm{p} \& \mathrm{p}\end{array}$

\section{New stock to order}

Sweaters

Lambswool fine knit, V-neck or round neck with small motif. Machine washable. State colour and chest size required.

Slipovers Lambswool fine knit, V-neck, with small motif. Machine washable. State colour and chest size required.

Sweatshirts

With small motif

State colour and chest size required.

Polo shirts

With small motif.

State colour and chest size required.

$£ 32+£ 1 p \& p$

$£ 30+£ 1 p \& p$

$£ 20+£ 1 p \& p$

$£ 18+£ 1 p \& p$

Send orders to: John H. Clegg JP LDS RCS Eng, Hon. Secretary, Birch Lea, 67 Springfield Lane, Eccleston, St Helens, Merseyside WA10 5HB, UK. (Tel: 0744 28198) 